\title{
New dual-stage pH control fed-batch cultivation strategy for the improvement of lipids and carotenoids production by the red yeast Rhodosporidium toruloides NCYC 921
}

\author{
Carla Dias, Sofia Sousa, João Caldeira, Alberto Reis, Teresa Lopes da Silva* \\ Laboratório Nacional de Energia e Geologia-LNEG, I.P., Unidade de Bioenergia, BBRI-Infraestrutura de Investigação em Biomassa e Bioenergia, Estrada do Paço do Lumiar, 22, \\ 1649-038 Lisboa, Portugal
}

\section{H I G H L I G H T S}

- Medium pH for the lipid and carotenoid production by $R$. toruloides is different.

- A dual step pH control fed-batch strategy improved the yeast products production.

- The oxygen played a crucial rule in the yeast carotenoid synthesis.

\section{A R T I C L E I N F O}

\section{Article history:}

Received 17 February 2015

Received in revised form 1 April 2015

Accepted 2 April 2015

Available online 8 April 2015

\section{Keywords:}

Rhodosporidium toruloides

Biomass

Carotenoids

Fatty acids

$\mathrm{pH}$

\begin{abstract}
A B S T R A C T
The optimal medium $\mathrm{pH}$ to produce biomass and fatty acids by the red yeast Rhodosporidium toruloides NCYC 921 is 4.0, and to produce carotenoids is 5.0. Based on this difference, a dual-stage pH control fed-batch cultivation strategy for the enhancement of lipids and carotenoids production by this yeast was studied. The results showed that when the yeast growth phase was conducted at $\mathrm{pH} 4.0$, and the products accumulation phase was conducted at $\mathrm{pH} 5.0$, biomass, total fatty acid and total carotenoid productivities were significantly improved comparing with the yeast fed batch cultivations carried out at fixed medium $\mathrm{pH}$ (4 or 5). Under dual-stage $\mathrm{pH}$ control conditions, the biomass, carotenoids and lipids productivities attained $2.35 \mathrm{~g} / \mathrm{L} \mathrm{h}, 0.29 \mathrm{~g} / \mathrm{L} \mathrm{h}$ and $0.40 \mathrm{~g} / \mathrm{L} \mathrm{h}$, respectively. It was also observed that the oxygen played a major role in the yeast carotenoid production.
\end{abstract}

(ㄷ) 2015 Elsevier Ltd. All rights reserved.

\section{Introduction}

The use of fossil fuels raises serious environmental concerns such as greenhouse gas (GHG) emission. Carbon dioxide is one of the GHG that contributes to global warming, causing the average surface temperature of the Earth to rise in response, which will cause major adverse effects to mankind. A global movement towards the generation of renewable energy is therefore under way to help reduce global greenhouse gas emissions.

Biodiesel is considered an ecological fuel as it is biodegradable, non-toxic and emits less gaseous pollutants than normal diesel (Kumar and Pal, 2014). However, biodiesel derived from the current sources (oil crops, waste cooking oil and animal fat) can only satisfy a small fraction of the existing demand for transport fuels (Chisti, 2007). Oleaginous microbes such as microalgae and yeasts can be used as biodiesel feedstocks. Indeed, these microorganisms

\footnotetext{
* Corresponding author.

E-mail address: teresa.lopessilva@lneg.pt (T. Lopes da Silva).
}

grow faster than crop cultures and their cultivation is non seasonal. Among oleaginous microorganisms, yeasts have a few advantages over bacteria, molds and algae, due to their higher growth rate, biomass and lipid productivities (Braunwald et al., 2013). Moreover, biodiesel production from yeasts is of particular interest for countries located at higher latitudes, where the daylight is not as long as in countries closer to the tropics, wherein autotrophic microalgae may be more suitable (Freitas et al., 2014a).

However, at the moment, biodiesel derived from microbes is still economically unsustainable, as its production costs are higher than first generation biodiesel (Schneider et al., 2013). Therefore, new strategies must be attained, in order to reduce the overall costs. If the microbial biomass, beyond its high lipid content, is rich in high value added products such as carotenoids (which have many applications in pharmaceutical, nutraceutical, food and feed industries, with a high market value) their commercialization may contribute to reduce the overall process cost (Lopes da Silva et al., 2014). 